\title{
Adaptação do método de Rugai e colaboradores para análise de parasitas do solo
}

\author{
Adaptation of the Rugai et al. method \\ for analysis of soil parasites
}

\section{Sílvia Maria Santos Carvalho ${ }^{1}$, Flávia de Assunção Gonçalves ${ }^{1}$, Pedro Costa Campos Filho ${ }^{1}$, Eunice Matos Guimarães ${ }^{1}$, Ana Pilar Souza González Y Cáceres ${ }^{1}$, Yasmine Barbosa de Souza ${ }^{1}$ e Letícia Carvalho Vianna ${ }^{2}$}

\section{RESUM0}

Este trabalho propõe a utilização de uma adaptação do método de Rugai e colaboradores que se presta à coleta de cistos, ovos e larvas de parasitas das areias das praias, parques e praças públicas.

Palavras-chaves: Método de Rugai. Cistos. Ovos. Larvas

\section{ABSTRACT}

This study offers an adaptation of the Rugai method for the collection of cysts, eggs and parasite larvae from beaches, parks and public squares.

Key-words: Rugai method. Cysts. Eggs. Larvae

Na tentativa de capturar cistos, ovos e larvas de helmintos de importância médica em parques, praias e praças públicas, alguns ensaios experimentais foram realizados, visando eficiência no desenvolvimento de um método, buscando praticidade e baixo custo. Desta forma, as adaptações empregadas no método de Rugai e cols ${ }^{4}$ fizeram com que os resultados saíssem a contento, cuja utilização se presta à análise de formas parasitárias presentes no solo. E interessante ressaltar que estes ensaios foram realizados com material recém-extraído de amostras fecais positivas, preservadas a $4^{\circ} \mathrm{C}$ por uma média de $5 \mathrm{~h}$ onde, sabidamente, tínhamos o conhecimento de quais parasitas estavam ali presentes, cientes da integridade física dos mesmos (Tabela 1). As amostras foram misturadas às porções de areia de duas praias do Maramata (praça no bairro do Pontal, onde funciona a Universidade Livre do Mar e da Mata), Concha e Prainha, município de Ilhéus, BA.

0 método consiste em colocar $100 \mathrm{~g}$ de areia em trouxas de gaze dobradas em oito ( $30 \mathrm{~cm} \mathrm{X} 30 \mathrm{~cm}$ ), mergulhadas em cálice de sedimentação, com capacidade para $125 \mathrm{~mL}$, em água a 45ํ․ Após $1 \mathrm{~h}$, a gaze é retirada e 0 material sedimenta por mais $1 \mathrm{~h}$.
Findo este tempo, se necessário, o material é lavado tantas vezes for conveniente, a depender da coloração do líquido sobrenadante. Essa lavagem consiste em desprezar este último, tendo o cuidado de não ressuspender ou perder o sedimento. Acrescenta-se mais água ( q.s.p. 125mL), deixando sedimentar por mais duas horas. Quando límpido, o sobrenadante é desprezado e 0 sedimento é transferido para tubos Wasserman e centrifugado a 2000rpm por 2 minutos. Aalíquota é colocada em lâmina, corada com o lugol, recoberta por lamínula e analisada em objetivas de 10X e 40X. Os resultados estão descritos na Tabela 1.

Tabela 1 - Protozoários e helmintos presentes em amostras de fezes utilizadas para o ensaio, e que foram recuperados na análise.

\begin{tabular}{lcc}
\hline Ovos & Cistos & Larvas \\
\hline Ascaris lumbricoides & Giardia lamblia & Strongyloides stercoralis \\
Ancilostomídeos & Entamoeba coli & Ancilostomídeos \\
Taenia sp & Entamoeba histolytica & \\
Trichirus trichiura & & \\
\hline
\end{tabular}

Vinte e quatro lâminas de cada praia foram analisadas. Todas as diferentes formas parasitárias, sem exceção, reapareceram

1. Departamento de Ciências Biológicas da Universidade Estadual de Santa Cruz, Ilhéus, BA. 2. Instituto de Ciências Biológicas da Universidade Católica do Salvador, Salvador, BA.

Trabalho financiado pela UESC (Universidade Estadual de Santa Cruz) e pela FAPESB (Fundação de Amparo à Pesquisa do Estado da Bahia) Endereço para correspondência: Dra. Silvia Maria Santos Carvalho. Rodovia Ilhéus/Itabuna, Km 16, 45.650-000, Ilhéus, BA.

e-mail: sissa@ uesc.br, sissacarvalho@ yahoo.com

Tel: 73 680-5268; Fax: 73 680-5226

Recebido para publicação em 14/7/2004

Aceito em 5/3/2005 
nas observações. Além disso, duas amostras-controle para cada praia foram também observadas onde, além de larvas de Ancilostomídeos, ovos de Toxocara canis foram visualizados, com a ressalva de que este último foi somente visto em amostras da praia da Concha. Vale ressaltar que ao final da primeira hora de sedimentação, foi possível ver, com 0 auxílio da lupa, em vidro de relógio, larvas em movimento.

Inúmeros trabalhos foram realizados na tentativa de capturar formas parasitárias de areias de parques, praças públicas e praias. A exemplo, pode ser citado o trabalho realizado em Santa Maria/RS2, onde os pesquisadores analisaram 5 amostras de solo, oriundas de 30 praças públicas, através da técnica de Caldwell \& Caldwell. A partir daí, constataram a contaminação por ovos de Ancylostoma spp, e nelas detectaram $93,3 \%$ de positividade. Por outro lado, em análise de 120 amostras pelo método de concentração em solução decinormal de hidróxido de sódio ${ }^{5}$, estudiosos pesquisaram a freqüência de contaminação por ovos de Toxocara spp em 10 parques e praças públicas de Botucatu/ SP, constatando 60\% de contaminação. Na cidade de Campo Grande/MS'1 em pesquisa realizada no ano de 1998 em 74 praças públicas, verificou-se a presença de ovos de Toxocara sp e Ancylostoma spp, utilizando a técnica de flutuação em solução saturada de açúcar e sedimentação espontânea, as quais detectaram 56,8\% de positividade para 0 gênero Ancylostoma, 10,8\% para ovos do gênero Toxocara, e 9,5\% das amostras continham formas parasitárias de ambas as espécies em estudo. Igualmente em análise de solo, no ano de 2000, em estudo realizado em 18 praias da cidade do Rio de Janeiro ${ }^{6}$, constatouse, através da aplicação do método de hidratação de ovos com solução de Ruffer, seguida de centrifugação, a presença de ovos de helmintos, detectando $2 \%$ de positividade. Adicionalmente, aplicando uma adaptação da técnica de Caldwell \& Caldwell ${ }^{3}$, em estudo realizado no município de Guaíba/RS, os pesquisadores estudaram três praias de rio, analisando 20 amostras de solo. Constataram então, a contaminação parasitária por cistos e oocistos de protozoários e ovos de helmintos em todas elas.

Aadaptação proposta para o método de Rugai e colaboradores apresenta algumas vantagens. Autilização de água a $45^{\circ} \mathrm{C}$ permite a captura de larvas em função do termotropismo e hidrotropismo positivos. A gaze dobrada oito vezes faz com que a quantidade de areia no sedimento seja mínima. As sucessivas lavagens, a depender da qualidade da areia, se fazem necessárias para facilitar a leitura das lâminas. Além do mais, a centrifugação do material se presta em concentrar, no sedimento, um maior número possível de parasitas. Adicionalmente, a mesma possui baixo custo quando comparada com algumas outras, e é perfeitamente viável do ponto de vista de ser utilizada na rotina laboratorial de pesquisadores que se prestam a este tipo de estudo.

\section{AGRADECIMENTOS}

À Daniella Oliveira Campos, pela revisão do trabalho.

\section{REFERÊNCIAS BIBLIOGRÁFICAS}

1. Araújo FR, Crocci AJ, Rodrigues RGC, Avalhaes JS, Miyoshi MI, Salgado FP, Silva MA, Pereira ML. Contaminação de praças públicas de Campo Grande, Mato Grosso do Sul, Brasil, por ovos de Toxocara e Ancylostoma em fezes de cães. Revista da Sociedade Brasileira de Medicina Tropical 32: 581583, 1999 .

2. Corrêa GLB, Moreira WS. Contaminação do solo por ovos de Ancylostoma spp em praças públicas, na cidade de Santa Maria, RS, Brasil. Revista da Faculdade de Zootecnia, Veterinária e Agronomia 2/3: 15-17, 1995/1996.

3. Laggagio VRA, Jorge LL, Oliveira V, Flores ML, Silva JH. Presença de endoparasitas em três praias do município de Guaíba-RS/Brasil. Disponível em: <www.redevet.com.br/artigos/praias.html> Acesso em: 30 jul 2002, 2000.

4. Rugai E, Mattos T, Brisola A. Nova técnica para isolar larvas de nematóides das fezes - modificação do método de Baermann. Revista do Instituto Adolfo Lutz 14: 5-8, 1954.

5. Santarém VA, Sartor IF, Bergamo FMM. Contaminação por ovos de Toxocara spp de parques e praças públicas de Botucatu, São Paulo, Brasil. Revista da Sociedade Brasileira de Medicina Tropical 31: 529-532, 1998.

6. Silva CAMC, Pastura CP 2000. Qualidade Sanitária das Areias de Praias do Município do Rio de Janeiro. Disponível em: http:// www.ciplima.org.pe/sanitaria/xxvii com/tema07/vii-001.pdf Acesso em: 29 jan 2003, 2000. 